Darwis Khudori (éd.), Religious Diversity in a Globalised Society. Challenges and Responses in Africa and Asia

Malang, Center for South-South Cooperative Studies, coll. «Bandung Spirit Book Series », 2013, 259 p.

\title{
Christophe Pons
}

\section{(2) OpenEdition}

\section{Journals}

Édition électronique

URL : http://journals.openedition.org/assr/28261

DOI : 10.4000/assr.28261

ISSN : $1777-5825$

Éditeur

Éditions de l'EHESS

Édition imprimée

Date de publication : 31 décembre 2016

Pagination : 333

ISSN : 0335-5985

Référence électronique

Christophe Pons, « Darwis Khudori (éd.), Religious Diversity in a Globalised Society. Challenges and Responses in Africa and Asia », Archives de sciences sociales des religions [En ligne], 176 | octobredécembre 2016, mis en ligne le 18 juillet 2017, consulté le 24 septembre 2020. URL : http:// journals.openedition.org/assr/28261 ; DOI : https://doi.org/10.4000/assr.28261

Ce document a été généré automatiquement le 24 septembre 2020.

(c) Archives de sciences sociales des religions 


\section{Darwis Khudori (éd.), Religious Diversity in a Globalised Society. Challenges and Responses in Africa and Asia}

Malang, Center for South-South Cooperative Studies, coll. «Bandung Spirit Book Series », 2013, 259 p.

Christophe Pons

\section{RÉFÉRENCE}

Darwis Khudori (éd.), Religious Diversity in a Globalised Society.

1 Cet ouvrage collectif - qui réunit les contributions de plus d'une vingtaine de chercheurs, anthropologues, sociologues, historiens, politistes mais aussi essayistes, journalistes, théologiens et acteurs du dialogue entre religions - doit être appréhendé comme la trace d'une série de débats et de communications qui eurent lieu en 2010, à la double occasion de la commémoration des cinquante-cinq ans de la conférence internationale de Bandung d'une part, et de la déclaration par les Nations Unies de l'année 2010 comme celle de la biodiversité d'autre part. Sous l'intitulé Diversity in Globalised Society: The Role of Africa and Asia for a Sustainable World, 55 Years after Bandung Asian-African Conference 1955, des auteurs majoritairement africains (Liban, Algérie, Nigéria, Kenya, Mali, Tanzanie, Côte d'Ivoire) et sud-asiatiques (Indonésie, Thaïlande, Philippines, Inde, Myanmar) ont tenu séminaires et ateliers dont rend compte l'ouvrage.

2 L'appétit du lecteur est ouvert par une préface évoquant la métaphore naturaliste, désormais entendue (et dont il faut rappeler qu'elle fit aussi l'objet d'une déclaration de l'UNESCO au lendemain du 11 septembre 2001, devenue ensuite une convention), selon laquelle la diversité religieuse est aussi nécessaire et importante à l'humanité que l'est 
la biodiversité à la nature. Mais l'enjeu de la pluralité religieuse devient dilemme sitôt qu'il implique d'organiser la reconnaissance effective d'une pluralité des universalismes, puisque chaque religion revendique être l'unique ; projet éminemment contradictoire, consistant à aménager l'universalisme et le relativisme. On regrette cependant que l'ouvrage ne soit pas à la hauteur des attentes escomptées et qu'il faille attendre les dernières sections, intitulées «Proposals " puis " Actions", pour que soient enfin abordées, d'une manière nuancée et non idéaliste, les modalités et prémisses de la construction d'un pluralisme religieux.

De la demi-douzaine de contributions de ces deux sections surgit une distinction majeure entre deux « modèles » de transformations; celui des contextes où la pluralité religieuse est historiquement fort ancienne, consubstantielle aux territoires peu à peu devenus des nations, et celui par ailleurs où la confrontation à la pluralité religieuse est un phénomène récent, dans des régions historiquement plus unitairement rassemblées autour d'une même religion. Au travers des cas indien (R. Susewind), tanzanien (F. Wijsen, S.Cholil, T. Ndaluka) philippin (M. Sinsuat Lidasan), kenyan (O. Gakuo Mwangi), nigérian (M. O.C. Kalu) et malien (M. Mara) est ainsi interrogée la manière dont sont appréhendés les effets différentiels d'une globalisation commune.

Dans sa chronique sur le post-indépendantisme nigérian, Kalu rappelle d'abord comment l'opposition chrétiens/musulmans a été l'outil par lequel fut scellé un autre conflit, historiquement non religieux, puis s'efforce d'envisager un dialogue inter-foi militant. Son propos fait écho à la stimulante réflexion du philosophe kenyan J. Gathogo autour de l'idée d'une "théologie africaine », à bâtir au croisement de deux notions-clés qui furent accolées à l'Afrique, celles d'homogénéité et de diversité : revenant sur l'histoire longue de ces deux notions, il cible l'unité à sceller dans le concept zulu d'ubuntu (hospitalité). Son papier résonne avec celui du politiste Mwangi qui, reprenant J. Habermas, interroge les concepts de «tolerance » et « religious toleration ». À l'instar du cas malien appréhendé par Mara, la plupart des auteurs suggèrent que les solutions à trouver sont du côté d'une sécularisation et d'un renforcement du rôle régulateur des États. Ceux-ci doivent ainsi promouvoir la connaissance des religions et leur régulation, en bâtissant une relation contractuelle entre eux, les acteurs religieux et les citoyens. Il reste que la plupart des États doivent faire face au handicap de leur propre incompétence et méconnaissance en matière religieuse, y compris lorsqu'ils sont eux-mêmes non-laïques.

5 Si Mara suggère que ce rôle de régulateur - que doivent endosser les États - n'implique pas de leur part qu'ils soient effectivement laïques, la plupart des contributeurs n'ont sans doute pas la même posture théorique dans la mesure où ils réaffirment un modèle évolutionnaire où le progrès transiterait par le suivi d'un modèle nordique. Les remarques conclusives manquent à ce titre de réflexivité, puisqu'elles réaffirment une alternative sociologique non questionnée, du type d'une opposition Gemeinschaft versus Gesellschaft. L'historien indonésien Faishal Aminuddin y désespère de voir un jour en Afrique et en Asie le progrès de la démocratie et de la sécularisation, ces deux «régions» du monde étant dit-il fondamentalement non libérales et non individualistes, donc communautaristes et enfermées dans des cadres moraux dont les valeurs sont en opposition avec celles de l'universalisme individualiste et libéral.

Or, ces remarques conclusives sont en accord avec celles qui donnent le cadre introductif et, plus largement, avec toute la première section de l'ouvrage intitulée " Diagnosis ». Cette section est la plus massive, tant sur le fond que la forme, avec douze 
contributions assez inégales qui, dans leur ensemble, composent une sorte de «livre noir " des monothéismes, conférant ainsi au terme diagnostique le sens quelque peu médical du constat des pathologies. L'islam et le christianisme y sont rapidement les cibles d'une critique acerbe qui les décrit comme hégémoniques et tyranniques. Le constat est clair: le monde allait bien mieux «avant», lorsqu'il se passait de ces religions universalistes, et il s'agit à présent de dresser un état des lieux de l'ampleur $\mathrm{du}$ désastre. Se succèdent alors des contributions inégales, mais fréquemment simplificatrices, qui soulignent comment les religions universalistes ont sans cesse combattu - et finalement supplanté - toutes autres formes religieuses locales (T. Koffi, H. Sagrim, P. Singh, C. Ndubuisi), comment le communautarisme religieux a imposé son dictat en brisant tout désir d'individualisme et en contraignant les systèmes juridiques nationaux (N. El Hage, L. Steckman, D. Khodori), comment toute identité ethnicoreligieuse minoritaire s'est retrouvée systématiquement persécutée par la majorité confessionnelle de l'une ou l'autre de ces religions (S. Lauhan, B. Labaki, M. Zarni), comment enfin les monothéismes sont devenus maittres dans l'exercice de l'oppression des femmes par les hommes (M. Kacimi, D. Buranajaroenkij). Dans ce panorama sans concession, il faut cependant reconnaître une absence manifeste de favoritisme au profit d'une dénonciation sévère de tout universalisme religieux : une incise inattendue pointe même le bouddhisme, une religion qui, selon Zarni, bénéficie d'une sympathie de principe en Occident, mais qui est pourtant responsable d'un génocide musulman à Myanmar.

Dès lors, cette première section et son introduction, qui campent la teneur militante et accusatrice de l'ouvrage, laissent le lecteur quelque peu perplexe tant la critique est sévère, sans appel, prenant parfois l'allure d'un plaidoyer peu innovant contre le christianisme et l'islam. Elle éveille cependant l'attention en cela qu'elle témoigne d'un front de réaction antireligieux qui a cours au sein d'Universités de l'hémisphère Sud, là où, précisément, un bras de fer est souvent plutôt engagé entre les acteurs militants des forces religieuses concurrentes. Mais Khudori argumente aussi cette posture en soulignant la singularité du double contexte Afrique-Asie. Dès l'introduction, il indique que l'Afrique-Asie est aujourd'hui l'ultime espace d'une résistance d'échelle globale, puisqu'on y trouverait encore une diversité religieuse qui partout ailleurs (Europe, Amériques du Nord et du Sud, Océanie) aurait cédé face à l'impérialisme mondialisé du christianisme. Asie et Afrique seraient cependant à leur tour très lourdement menacées par les universalismes religieux conquérants, d'abord celui du christianisme, ensuite attisé par la concurrence de l'islam. Ce point de vue est notamment repris pour l'Afrique par plusieurs contributions (Koffi, Sagrim, Singh) qui accusent l'impérialisme d'avoir procédé par voie de «diabolisation » des religions locales et coutumières; la sortie de l'impérialisme - et par là même le projet d'un espoir pour l'Afrique - doit dès lors transiter par une réappropriation des spiritualités confisquées, c'est-à-dire celles qui furent systématiquement érigées en sorcellerie. Or, là encore, si l'accusation est radicale, elle n'est cependant pas dénuée d'intérêt en cela qu'elle pointe malgré tout un fait historique de "démonologisation » toujours d'actualité. Que ce soit au travers de la tradition ethnologique, ou bien des intarissables actions et discours des Églises pentecôtistes, et même à présent des projets consistant à élever des rituels locaux au rang de « patrimoine culturel immatériel » - processus de reconnaissance culturelle qui vide dans le même temps de toute charge et efficacité symbolique -, la conception historiquement construite qui prévaut toujours dans les instances internationales de régulation et de développement ( $\mathrm{ONG}, \mathrm{ONU}$, etc.) est bien que les « religions locales »- 
rapidement assimilées/associées à des pratiques/systèmes sorcellaires - peuvent devenir de périlleuses croyances, nourries d'ignorance, d'insécurité, et de l'incapacité récurrente des États africains à jouer le rôle régalien qu'une idéologie de la modernité suppose. Or, c'est bien en usant de cette conception historiquement façonnée que se dresse le christianisme, affichant son programme militant de libération, de progrès et de modernité.

8 Religious Diversity in a Globalised Society est un ouvrage inattendu, qui oscille entre de notables contributions et d'autres clairement irritantes du fait de leur ton militant et de leur promptitude à réduire les universalismes religieux à des organisations tyranniques. En cela l'ouvrage s'adressera-t-il sans doute, en priorité, aux convaincus. Et à ce titre, il questionne aussi quant aux modèles universalistes qui sont théorisés au Nord puis rabattus au Sud; car ici, en effet, toute la lecture critique à l'encontre des ravages des monothéismes est portée par un quatuor idéaltype peu remis en cause, associant libéralisme, individualisme, démocratie et sécularisation. En dernière instance, si l'ouvrage mérite attention, c'est aussi - et surtout - parce qu'il constitue une sorte de baromètre indiquant la teneur de propos contemporains en provenance des Sud, issus de contextes où, singulièrement aujourd'hui, les voix dissidentes areligieuses méritent de ne pas être tues. 